\title{
Carbon dioxide-induced amnesia in the cockroach Periplaneta americana
}

WILLIAM C. FRECKLETON, Jr., AND DOUGLAS WAHLSTEN, DEPARTMENT OF PSYCHOLOGY, UNIVERSITY OF CALIFORNIA, Irvine, California 92664

Cockroaches (Periplaneta americana) learned to passively avoid electric shock in a two-compartment box after a single training trial. However, $\mathrm{Ss}$ exposed to $\mathrm{CO}_{2}$ gas immediately after the training trial failed to show retention of the previous experience when tested $24 \mathrm{~h}$ later. Results obtained are consistent with those observed in studies of retrograde amnesia in vertebrates.

Numerous studies of humans, rats, mice and fish have shown impaired retention of learned tasks due to the administration of various convulsant and anesthetic agents (McGaugh, 1966). These studies have generally supported the consolidation hypothesis, which states that the establishment of permanent memory of an experience depends upon the continuing activity of a labile memory trace for a period of time following that experience. Presumably, such agents as ECS, drugs, anesthetics and concussion act by disrupting the labile memory trace and thereby prevent formation of the long-term trace.

Despite the considerable differences between the supraesophageal ganglia of cockroaches and the encephalized central nervous system of vertebrates (Hughes, 1965), researchers have found cockroaches to be capable of learning active avoidance (Minami \& Dallenbach, 1946), passive avoidance (Ebeling, Wagner, \& Reierson, 1966) and food-motivated tasks (Longo, 1964), as are most vertebrates. Given that rapid learning can occur in insects, the present experiment studied the use of $\mathrm{CO}_{2}$ gas as an amnesia-inducing agent with an invertebrate in order to examine the phyletic generality of consolidation-like processes. It was hypothesized that administration of a convulsant or anesthetic agent to cockroaches immediately following a trial of passive avoidance learning would greatly reduce retention during later testing as compared to ungassed Ss. The agent to be used was gaseous $\mathrm{CO}_{2}$, which has long been used by entomologists for immobilizing insects prior to surgery and various procedural manipulations (Williams, 1946). When the gas is applied to cockroaches, gross muscular contractions begin within 5 to $10 \mathrm{sec}$ and are followed by 3 to $5 \mathrm{~min}$ of immobility.

\section{EXPERIMENT 1}

\section{Method}

The Ss were 30 adult male $P$. americana cockroaches of undetermined age, which were housed singly in plastic containers with free access to dry dog food and water.

The experimental chamber was a black $9 \times 3 \times 4$ in. Plexiglas box with a vertical sliding door partitioning it into two equal halves. The floor on one side was a shock grid of $1 / 4$ in. stainless

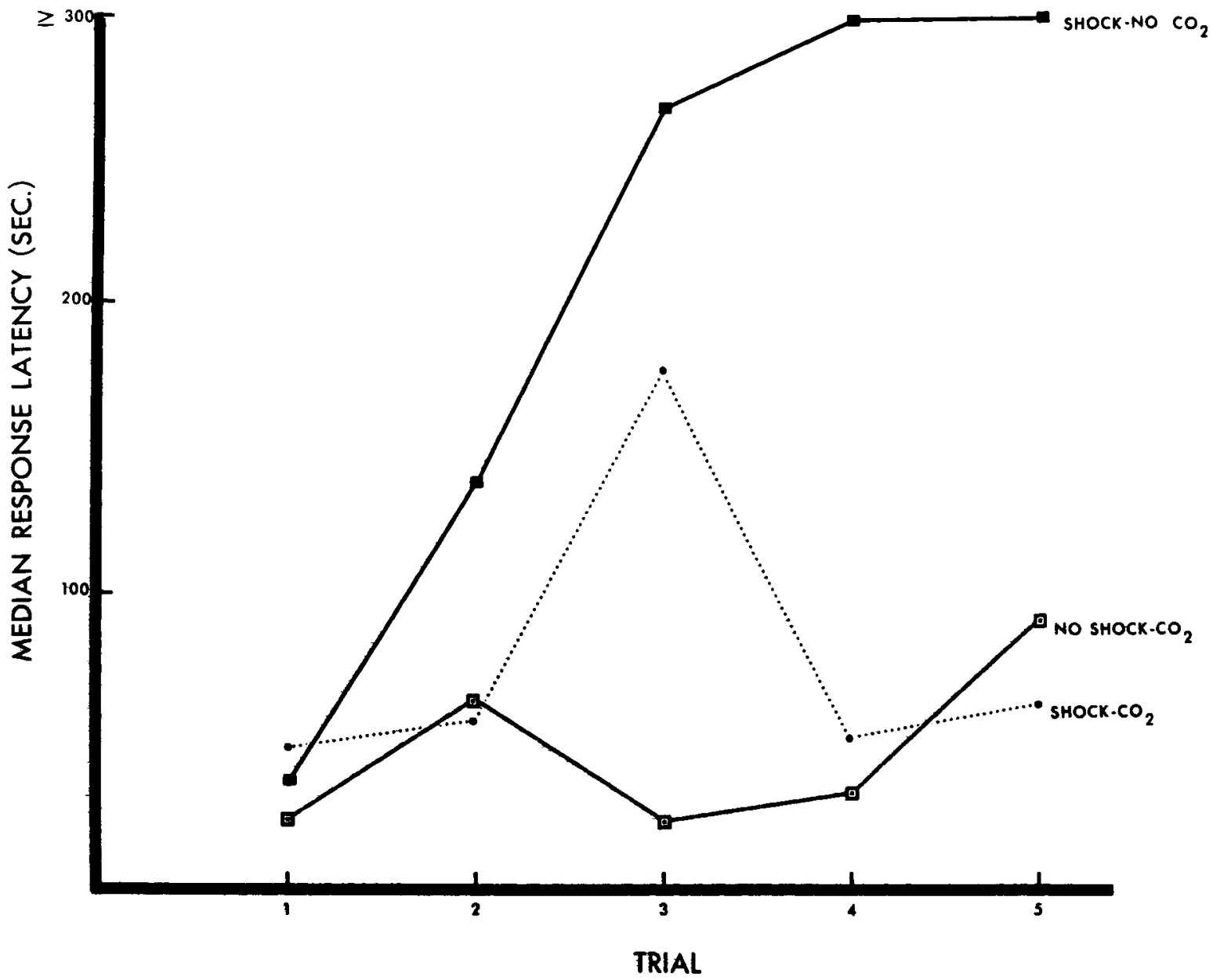

Fig. 1. Median latencies to cross onto grid on each of five triats. 
steel strips, while the other half had a Plexiglas floor. Vaseline was spread thinly on the sides of the box to prevent Ss from climbing the walls. Shock on the grid was $10 \mathrm{~V}, 60 \mathrm{~Hz}$ from a Superior Electric Powerstat. A plastic Nalgene No. 120 millipore filter served as the gassing chamber and was connected via rubber tubing to a tank of $\mathrm{CO}_{2}$ gas. Response latencies were measured to the nearest $.5 \mathrm{sec}$ with a stopwatch.

In this experiment the $\mathbf{3 0} \mathrm{Ss}$ were divided into three groups of 10 Ss each: A shock- $\mathrm{CO}_{2}$ group, in which $\mathrm{Ss}$ were shocked as they touched the grid and were then gassed; a Shock-No $\mathrm{CO}_{2}$ group, in which Ss received shock on the grid but were not gassed; and finally a control group, No Shock- $\mathrm{CO}_{2}$, whose Ss were never shocked but received gas after touching the grid.

Each $S$ received a single trial per day for five consecutive days. The procedure for all groups was to drop the $S$ onto the safe side of the box with the door down. Then, as the door was raised, a stopwatch was started to measure the time taken for the $S$ to touch the grid. After touching the grid, $S$ was removed from the box with a pair of metal forceps and, according to its group, gassed within $15 \mathrm{sec}$ or retired to its home quarters. Gassing was accomplished by placing the $S$ in the upper chamber of the bi-chambered filter and letting the $\mathrm{CO}_{2}$ seep into the lower half for $15 \mathrm{sec}$. At the end of $15 \mathrm{sec}$ in the chamber, $\mathrm{S}$ was returned to its home quarters. Similarly, one additional training trial was given on each of the next four days. If $S$ failed to cross to the grid within 5 min on any trial, it was removed and returned to its home quarters.

Results

The median latencies to step onto the grid for each group on the five trials are shown in Fig. 1. Since the latencies frequently reached the upper limit of $5 \mathrm{~min}$, all statistical comparisons were made with nonparametric tests on ranks, using the Kruskal-Wallis analysis of variance $(\mathrm{H})$ to compare independent groups and the Wilcoxon signed-rank test (T) for matched pairs. Latencies of the three groups did not differ on the first trial $(\mathrm{H}=0.77$, $\mathrm{df}=2$ $\mathrm{p}>.10$ ), while a significant difference appeared on the second trial $(\mathrm{H}=6.01, \mathrm{df}=2, \mathrm{p}<.05)$. Neither the Shock- $\mathrm{CO}_{2}$ nor the No Shock- $\mathrm{CO}_{2}$ groups changed significantly from Trial 1 to Trial 2 , while the Shock-No $\mathrm{CO}_{2}$ group had longer latencies on its second trial $(T=3, p<.005)$. Thus, learning of the passive avoidance after one trial was demonstrated only for the ungassed group. This finding continued to hold with repeated trials; neither of the groups receiving post-trial $\mathrm{CO}_{2}$ showed significant latency change over the five trials. On the fifth trial for the Shock-No $\mathrm{CO}_{2}$ group, however, only two Ss crossed onto the grid within the 5 min limit, indicating a high level of passive avoidance.

$$
\text { EXPERIMENT } 2
$$

In the first experiment several Shock-No $\mathrm{CO}_{2}$ Ss, while avoiding the grid, moved their antennae close to the grid without actually touching it. To investigate the possibility that Ss were using their antennae to detect the voltage without actually being shocked, an additional $10 \mathrm{Ss}$ were run with a $15 \mathrm{~V}$ shock on the grid during the first training trial but with no shock present during the test trial $24 \mathrm{~h}$ later. In this way Ss could not avoid the grid on the test trial by sensing the electric field. However, there was a significant increase in crossing latencies between the first and second trials ( $T$ $=5, \mathrm{p}<.01)$. These results were similar to those for group Shock-No $\mathrm{CO}_{2}$ in Experiment 1. Thus, the apparent learning was not due to detection of the voltage before the shock occurred to the legs.

\section{Discussion}

Although the present findings demonstrate that the administration of $\mathrm{CO}_{2}$ gas to cockroaches soon after a training trial can lead to impaired performance in passive avoidance and are thereby consistent with the consolidation hypothesis, several questions remain to be answered before conclusions are drawn concerning the phyletic generality of consolidation-like processes. First, does the memory in the ungassed Ss actually become permanent and yield retention at intervals longer than $24 \mathrm{~h}$ ? Second, does the presumed permanent trace increase in durability with increasing time following training? Several different training- $\mathrm{CO}_{2}$ and training-testing intervals clearly need to be examined in order to determine whether a temporal gradient of memory exists in the cockroach. Finally, are the presumed amnesic properties of the $\mathrm{CO}_{2}$ gas due to its convulsant, anesthetic or even peripheral sensory-motor effects? Can other gasses or anesthetics impair retention? Knowing the precise mode of action of an amnesiainducing agent would allow much stronger inferences to be made concerning the nature of memory storage and retrieval. Additional experiments are currently in progress which attempt to resolve some of these issues.

\section{REFERENCES}

EBELING, W., WAGNER, R. E., \& REIERSON, D. A. Influence of repellency on the efficacy of blatticides. 1. Learned modification of behavior of the German cockroach. J. Econ. Entomol, 1966, 59, $1374-1388$.

HUGHES, G. M. Neuronal pathways in the insect central nervous system. In J. Treherne and J. Beament (Eds.), Insect central nervous system. New York: Academic Press, 1965.

LONGO, N. Probability learning and habit-reversal in the cockroach. Amer. $J$. Psychol, 1964, 77, 29-41.

McGAUGH, J. L. Time-dependent processes in memory storage. Science, 1966, 153, 1351-1358.

MINAMI, H., \& DALLENBACH, K. M. The effect of activity upon learning and retention in the cockroach. Amer. J. Psychol, 1946, 59, 1-58.

WILLIAMS, C. M. Continuous anesthesia for insects. Science, 1946, 103, 57. NOTE

1. Cockroaches were supplied by Dr. Walter Ebeling of UCLA Department of Entomology, and gassing apparatus was supplied by Dr. Ronald L. Taylor of University of California, Irvine. Reprints may be obtained from. D. Wahlsten, Institute for Behavioral Genetics, University of Colorado, Boulder, Colorado, 80302. 